\title{
BMJ Open Illness perception and coping among women living with breast cancer in Ghana: an exploratory qualitative study
}

\author{
Nuworza Kugbey (D) , ${ }^{1}$ Kwaku Oppong Asante, ${ }^{2,3}$ Anna Meyer-Weitz ${ }^{4}$
}

To cite: Kugbey N, Oppong Asante K, Meyer-Weitz A. IIIness perception and coping among women living with breast cancer in Ghana: an exploratory qualitative study. BMJ Open 2020;10:e033019. doi:10.1136/ bmjopen-2019-033019

- Prepublication history and additional material for this paper are available online. To view these files, please visit the journal online (http://dx.doi. org/10.1136/bmjopen-2019033019).

Received 16 July 2019

Revised 20 December 2019

Accepted 15 January 2020

A Check for updates

(C) Author(s) (or their employer(s)) 2020. Re-use permitted under CC BY-NC. No commercial re-use. See rights and permissions. Published by BMJ.

${ }^{1}$ Department of Family and Community Health, University of Health and Allied Sciences, Ho, Ghana

${ }^{2}$ Department of Psychology, College of Humanities, University of Ghana, Accra, Ghana

${ }^{3}$ Department of Psychology, University of the Free State, Bloemfontein, South Africa ${ }^{4}$ Discipline of Psychology, College of Humanities, University of KwaZulu-Natal, Durban, South Africa

Correspondence to Dr Nuworza Kugbey; nkugbey@uhas.edu.gh

\section{ABSTRACT}

Objective Illness perception has been shown to have significant influence on the well-being and coping strategies of persons living with chronic medical conditions. Understanding of how women living with breast cancer cognitively and emotionally represent their illness and coping strategies used is likely to help in designing focused psychosocial interventions aimed at improving their health and well-being. This study explored the illness perceptions and coping strategies among women receiving care for breast cancer.

Design A qualitative phenomenological study (using semistructured in-depth interviews).

Setting Oncology department of a tertiary hospital in Ghana.

Participants Eleven women receiving breast cancer treatment were purposively sampled and in-depth individual interviews were conducted with questions based on illness perception and coping literature.

Results In terms of illness perceptions, it emerged that most of the participants lacked adequate factual knowledge about breast cancer and perceived causes but believed in the curability of their illness through medical treatments and the help of God. Spirituality, social support and diversion coping were the key resources for coping among the participants.

Conclusion Breast cancer patients lacked adequate factual knowledge of breast cancer and their perception about the causes of breast cancer is rooted in biopsychospiritual model of illness. The reliance on spirituality and social support as the main coping strategies suggests the need for psychosocial interventions tailored to the spiritual and psychosocial needs of the patients.

\section{INTRODUCTION}

Living with breast cancer presents women with significant challenges that they must deal with as the illness interferes with their physical, social, psychological, economic and spiritual lives. ${ }^{12}$ These challenges have been found to be the major contributing factors to decreased health-related quality of life among women living with breast cancer. ${ }^{3-5}$ Evidence suggests that women diagnosed with breast cancer differ in their reaction to the illness and that these reactions in turn influence their coping strategies and disease management. ${ }^{6}$
Strengths and limitations of this study

This study is the first of its kind, which comprehensively explored illness perceptions and coping strategies among breast cancer patients.

- Findings from this study have laid the foundation for more psycho-oncology research focused on understanding biopsychosocial issues associated with living with breast cancer to inform evidence-based interventions.

- The sample included breast cancer patients receiving oncology care at only one referral hospital and findings may not represent the views of patients located at other parts of Ghana.

Breast cancer patients' cognitive and emotional representations of their illness becomes a critical aspect of the healthcare delivery process, which cannot be overlooked. This is because patient-centred care requires health professionals to take the needs and views of patients into consideration to ensure satisfaction and thus, improved health outcomes. ${ }^{7}$ Illness perceptions among breast cancer patients have been linked to several health outcomes, including depression, anxiety, physical and mental quality of life..$^{8-10}$

However, the specific sociocultural and socioeconomic contexts may influence patients' perception and understanding of their illness, which are inextricably linked with their lived experiences. The interrelationships among the entire experiences of the women living with cancer suggest that the socioeconomic and sociocultural factors may impact on how patients make meaning of their illness and these illness representations may influence the lived experiences of the patients. ${ }^{11}$ Thus, the relationships among these factors are multidimensional and may sometimes revolve in a cycle as the lived experiences may also influence the socioeconomic status and illness perception of the patients. These represent significant challenges confronting women living with breast cancer. 
In dealing with the multitude of challenges, various coping strategies are employed. ${ }^{12-15}$ It has been argued that coping plays a major role in the lives of persons diagnosed with chronic medical conditions, including breast cancer. ${ }^{14}$ As noted earlier, the illness representations of the women living with cancer are likely to influence the type of coping strategies they adopt in trying to adjust with the burden of the medical treatment and living with the disease. ${ }^{16}$ Evidence suggests that spirituality, social support, acceptance, cognitive restricting and avoidance are common coping strategies used by women living with breast cancer. ${ }^{12} 1315$ These coping strategies among breast cancer patients significantly influence their health outcomes. ${ }^{17}$

However, contextual and cultural differences may influence the illness representation and coping strategies that are employed by women living with breast cancer in a low-resourced healthcare setting like Ghana. ${ }^{18}$ Studies conducted in Ghana among women diagnosed with various cancer types have showed that surrendering to God, illness acceptance, the will to live and self-care practices were key coping strategies used. ${ }^{1819}$ These studies, however, did not consider examining both cognitive and emotional representations of breast cancer and how these perceptions may influence coping strategies. Additionally, there are inadequate qualitative studies exploring cognitive and emotional representations of breast cancer as most of the studies were either cross-sectional or longitudinal examining the impact on health outcomes. ${ }^{6}$ There is paucity in the literature regarding illness representation and coping strategies used by women living with breast cancer in Ghana. This study was, therefore, conducted to explore illness perception and coping strategies used by women living with breast cancer in Ghana. It is believed that this information would provide practitioners and researchers with the roadmap to improving the health and well-being of women living with breast cancer as their illness perceptions are most likely to inform treatment choice and overall health-seeking behaviours.

\section{METHODS}

\section{Research design and research setting}

A qualitative research design (phenomenology rooted in the interpretivist paradigm) was employed to understand the lived experiences of breast cancer patients regarding their illness representation and the coping strategies they adopt in their breast cancer journey. The population for this study consisted of all women diagnosed with breast cancer and receiving treatment at the Radiotherapy and Nuclear Medicine Department of the Korle-Bu Teaching Hospital (KBTH) in Ghana, West Africa. The KBTH is one of the tertiary hospitals and the oldest in terms of healthcare provision in Ghana. Patients who access healthcare at the KBTH are usually referred from the smaller health facilities. This hospital caters for all patient groups regardless of socioeconomic
Table 1 Demographic profiles of the respondents in the study

\begin{tabular}{ll}
\hline Variables & Frequency \\
\hline Age range & 6 \\
\hline $40-49$ & 2 \\
\hline $50-59$ & 2 \\
$60-69$ & 1 \\
\hline 70 years and above & \\
\hline Marital status & 2 \\
\hline Single & 6 \\
\hline Married & 2 \\
\hline Widowed & 1 \\
\hline Re-married & \\
\hline Level of education & 4 \\
\hline Basic/primary education & 5 \\
\hline Secondary education & 2 \\
\hline Fourth year & \\
\hline Employment status & 3 \\
\hline Self-employed & 2 \\
\hline Employed & 3 \\
\hline Retired & 3 \\
\hline Unemployed & 10 \\
\hline Religion & 1 \\
\hline Christian & 1 \\
\hline Muslim & 7 \\
\hline Years lived with illness & \\
\hline Less than 1 year & \\
\hline 1-5 years & \\
\hline $6-10$ years & \\
\hline 11 years and above & \\
\hline
\end{tabular}

status. The National Health Insurance Scheme covers part of the cancer treatment, but patients still bear some of the cost not covered by the scheme. ${ }^{20}$

\section{Participants and sampling}

A total of 11 women receiving treatment for breast cancer were purposively sampled after they were initially recruited for a quantitative study. ${ }^{4}{ }^{14}$ This sampling approach was adequate for the study as it allowed the researchers to select participants who would be able to provide critical and in-depth information necessary to achieve the objectives of the study. Participants included in the study were between the ages of 46 years and 71 years. The majority of the participants were between the ages of 40 years and 49 years with an average age of 56.5 years. All of the participants except one reported to be a Christian. The majority of the participants were married $(n=6)$ and had secondary level education $(n=5)$. Specific demographics of the participants are presented in table 1. 


\section{Patient and public involvement}

There was no patient or public involvement in setting the research agenda.

\section{Data collection procedure}

An interview guide (online supplementary appendix 1) was used to conduct in-depth individual interviews with participants living with breast cancer to explore their illness perception and coping strategies within the Ghanaian context as culture influences the perceptions causal attributions and experience of illness. ${ }^{21}$ Participants were visited in their homes and their informed consents were obtained after the purpose of the study was explained to them. Permission to record the interview was sought and granted by the participants. The semi-structured interview that guided the interview process focused on two main areas: illness perception and coping strategies. The responses from the participants were used to generate further probing questions for clarifications as the interview guide allowed for flexibility. The data collection lasted between September 2017 and January 2018. The individual interviews lasted between $30 \mathrm{~min}$ and $60 \mathrm{~min}$.

\section{Data analysis}

Verbatim transcription of the audio recording was done. This was to ensure that the views expressed by the participants are not distorted. Most of the participants could speak English and thus, all the interviews were conducted in English with few local language interjections to emphasise their views. These interjections were appropriately translated as the researchers understand the predominant Ghanaian language (ie, Twi). The interpretative phenomenological approach which involves exploration of participants' own subjective real-life experiences with no attempts at measuring the objectiveness of the experiences of the women living with breast cancer was used. $^{22}$ The analysis used the four principles and guidelines (gaining an understanding of the transcribed interview by reading and re-reading of the data and identifying points of interest, linking identified and harmonised quotes together to form themes, making connections with identified themes, and summarising main themes together with their subthemes with their appropriate quotations) recommended by Storey. ${ }^{23}$ In following the guidelines stated above, the researchers read and re-read the transcribed data, which allowed for an in-depth understanding of the views of the participants. The researchers proceeded to make meaning of the data and developed themes to encapsulate the views expressed by the participants. Subthemes were developed to elaborate on the dimensions of the major themes that emerged from the data. The subthemes were supported with direct quotes from the narratives of the participants for emphasis.

\section{RESULTS}

\section{Illness representation}

This main theme describes participants' cognitive and emotional representations of their illness. Participants understanding and meanings of breast cancer are likely to influence their lived experiences. Three sub-themes were identified under this theme, namely, breast cancer knowledge, perceived causes of breast and duration/ curability of breast cancer.

\section{Knowledge of breast cancer}

Factual and accurate knowledge about breast cancer is likely to help patients in their adjustment to their illness as it may minimise the uncertainties surrounding breast cancer. Two key dimensions of breast cancer knowledge emerged among the patients, that is, those who have no factual knowledge and those who have some factual knowledge about breast cancer. The majority of the participants do not have any factual knowledge about breast cancer as illustrated by a narrative from one of the participants:

as a matter of fact, if you ask me, I wouldn't know even before the thing (breast cancer) happened, I had not heard of the name before and in my family, I had not heard that anyone has had that disease before. (P6)

Contrary to the above, some of the participants had some factual knowledge about what breast cancer is with emphasis on the biological changes in the cells of the breast as illustrated below:

It starts with the lump. I think when you go (to the hospital) earlier, they can just take the lump out for you. When you don't see it and it spreads, that's when it becomes cancerous...Like I told you, at the initial stages, I thought it was meant for old ladies who'd given birth already, sixty years upwards. That was what was in my mind. That was how I knew breast cancer to be. Nowadays in your thirties and forties, if you're not careful, you'll get it. (P4)

\section{Perceived causes of breast cancer}

Participants in the study had varied views about their perceived causes of breast cancer. Whereas a substantial number of the women stated that they did not know what causes breast cancer, others mentioned supernatural forces, physiology and stress as the possible causes of their illness. The narrative illustrates the ambivalence on the cause of breast cancer from a participant:

I do not know my child (referring to interviewer). As for me...hmmm...I do not know. Sometimes, they say it is a family sickness or runs through the family, but my mother did not experience this, neither did any member from my father's family experience this... hmmm...so my child (interviewer)...I don't know ooo. (P8)

Some of the participants perceived their illness to have some underlying supernatural causes and these perceived causes were influenced by what they have heard from people and their own beliefs. This is illustrated in the narrative below: 
Ah....as for me... I do not know if I was shot spiritually or the sickness came on its own. As for me, in all things, I just give it to God. I also told you earlier that I had a dream that I was being shot. Where I had the gunshot in the dream is the same place that I experienced the cancer in the breast. (P7)

Another participant emphatically stated that she is convinced that extreme stress from her work might have caused her breast cancer:

....as for mine (breast cancer), I suspect stress...high level of stress... I am not someone who lives a careless life. By nature, I am the prudent type in all aspects of life...eating... whatever. I have never even taken alcohol before in my whole life. I do not even know how it tastes... and I am not someone who leads reckless life. You see...they said this disease is a lifestyle related problem. My psychologist sat with me trying to find out my family life and I realized that the only thing that I did that my body kept signaling me that I didn't head to was stress. High levels of stress. Otherwise, my eating level is not bad, my marriage is not bad, my children are grown, and it is not like I had little children giving me pressure at home. In fact, I realized that it was more work-based. Because at a point in time, I was always having breakdowns. For about 3 years, my white blood cells were not functioning properly, so I was on immune boosters and all manner of supplements. (P11)

\section{Duration/curability of breast cancer}

From the analysis, it was not possible to separate illness duration from curability as most of the participants linked duration to curability. A substantial number of the participants were of the view that their breast cancer can be completely cured with medical treatments and the help of God. However, some of the participants were not sure of the curability of the disease. The participants went further to provide reasons for their perceived duration/ curability of their breast cancer as illustrated below:

Nothing is too hard for the Lord. God can do a lot of miracles. God also uses doctors to perform his miracles. That is why I always run to doctors when I am sick...as for me...with the treatment I am currently going through...I know of someone who started with it since the year 2000 and the person is still alive and kicking. Nothing has happened to her...So I know that God will also have favour on me so that I can be healed completely. (P10)

Aww...according to people...For instance, my siblings showed me one woman who has been treated of breast cancer for about 18 years now. A lot of people...even in my church...there are people I know have been cured of the disease....almost about 4 people. They all confessed to have gotten some but now, they have been cured. What I have realized to be the most difficult aspect is the chemotherapy...if I try my best and go through the process, I know I will be fine. There was one woman who also testified that she had this disease when she was 71 just like me and now she is $82 \ldots$ she is very strong. She told me that if I am able to go through all the processes, I will become stronger than how I am now. However, I don't really know how long my sickness will last. (P8)

However, a participant was of the opinion that she is uncertain about the duration/curability of her sickness since the causes are not even known in the first place:

I don't really know because like we are saying...I don't know the root cause. Sometimes, they say it is from your diet...sometimes but I don't really know. I can't tell because we haven't found the real cause of the disease...so to say it can be done away completely....I am not sure...I believe with the mastectomy and radiation, it will go away very soon... because of the treatment and my faith in God. (P9)

\section{Coping with breast cancer}

This theme describes ways in which persons living with chronic medical conditions such as breast cancer adjust to their life circumstances. In their adjustment process, they employ several coping strategies that may influence both their short-term and long-term health outcomes. Three key coping strategies emerged from the interviews: the use of spirituality/religious coping, social support and seeking diversion. However, it is important to note that the participants in the study did not rely on only one form of coping but a myriad of strategies, all aimed at helping to adjust to the disease and improve their quality of life.

\section{Spirituality/religious coping}

Almost all the participants mentioned that breast cancer and its treatment has drawn them closer to God/Allah. That is, they were of the view that living with breast cancer and undergoing the difficult medical treatments have strengthened their faith in God/Allah and helped them in dealing with the challenges associated with living with breast cancer. Some of the participants engaged in several religious activities such as daily prayers and rituals to help them cope with their condition, that is, in building of hope, financial provision, healing and acceptance of their health condition as reflected in the quotations below:

...It has rather strengthened my faith because... you know...when something happens to you, as a Christian, you trust God that, He is your healer, so it has strengthened my faith in God that He will heal me...even though the doctors are working on it. $\mathrm{He}$ is the ultimate Healer. (P9)

Apart from religiosity and spirituality providing hope and healing to the participants, reliance on God served to provide companionship to some participants. This helps women to make meaning of their social role limitations and viewed God as their hope and source of comfort: 
...I think it (breast cancer and its treatment) has even made me much stronger because at a point in time, I didn't have anybody apart from God. So, it has rather drawn me closer to God... just that some roles that I was playing in church, because I am now not too regular in church, I am not able to play those roles because of the sickness but I am very close to God than before. (P11)

On the other hand, the use of spirituality as a coping mechanism is influenced by the participants' belief that their disease is a test from God, which they must pass, and, therefore, will not give up.

I think it is just a test from God...hmm because one cannot live His life just like that, if you say you believe in God He will never leave you like that. He tests you to see whether it is true you believe in Him and whether you will divert your faith somewhere. This is what my faith tells me. He has brought it and shown me a way out of it. (P2)

These quotes from the participants indicate that God or a supreme being plays an important part in the breast cancer journeys of these women and thus, may subsequently influence their perception of the illness and overall health outcomes through acceptance, hope, companionship and meaning making.

\section{Social support}

From the narratives, social support in the forms of emotional, financial and instrumental support emerged as key coping strategies. Social support plays a significant role in the overall coping with the disease. One thing that run through all the narratives was social support from immediate family. Below are some direct quotes from participants regarding the value of social support in coping:

I think I have my family with me...they understand and give me the necessary support, so I am okay...I am ok...apart from the few side effects here and there...the family is always there as they used to. (P9)

... I'm here with my dad, he takes care of me, so he sees me. If there's any help, he assists me. Those abroad, especially my mum, she calls me every day. She calls to check-up on me and find out how I am doing, because she's not here (in Ghana)... My brothers too support me with money. (P3)

\section{Diversion coping}

A substantial number of the participants in the study also reported the use of diversion coping strategies, which include listening to music, or religious sermons and/ or watching movies to take their minds off their breast cancer. For participants who use songs and inspirational messages, one woman reported that:

I love songs ...so I have a lot of songs on my phone which I listen to. Sometimes on the television too...
Mostly, gospel songs. A few friends who are also aware of the situation do send me inspirational messages. When I read them, it encourages me. You are a Christian but sometimes, you get down as a human being. You need to encourage yourself, so I like reading them. (P11)

Other participants use either television alone or both as illustrated by the following direct quotes from the participants:

...oh I watch movies if I am at home, you see once a while you will laugh err if it's emotional too you say aww and I watch movies, I like watching movies not any movie at all but movies that encourage and inspire me or make me laugh... local, foreign. You see some movies... you learn from them, you learn from them maybe like somebody has done something and you see it you would not want to do it because of the end results 'ahaa' so I like watching movies, movies that will educate you. You see, not any movie at all, will educate you, encourage you or teach you lesson. I also like music, I listen to music a lot especially, gospel, even these local music like the ones by Ampofo Adjei (a Ghanaian musician) and co if you listen to the words and lyrics in the song you can see that they inspire you. (P4)

These quotes from the participants suggest that radio and television may play significant roles in their breast cancer journey as it may serve to help them cope and as a potential source of life lessons that might be meaningful to them.

\section{DISCUSSION}

This study explored illness perception and coping among women living with breast cancer in Ghana. This study filled an important gap in scientific literature as few studies within the Ghanaian context have explored illness representation and coping strategies used by women living with breast cancer. We found that participants' cognitive and emotional representations of their illness was influenced by three main factors, namely, their knowledge about breast cancer, perceived causes of breast cancer and duration/curability of breast cancer. It was also found that participants used three key coping strategies: spirituality/ religious coping, social support and seeking diversion as resources for survival against the emotional and psychosocial challenges for patients living with breast cancer.

The lack of adequate factual knowledge about breast cancer as found in this study has consequences for patients' illness perception and treatment outcomes. ${ }^{24-26}$ This is because perceptions of the causes of breast cancer could influence patients' ability to adhere to medical treatments as erroneous beliefs may lead to seeking alternative healthcare from unapproved sources. ${ }^{27}$ In terms of patients' perception of the curability and duration of their illness, we found that the majority of the 
participants believed that their illness can be completely cured; and that they believe they can live long with their illness as long as they have faith in God and adhere to medical treatments. This perception of the curability and duration of the illness is rooted in the personal faith of the participants as reference to God ran through all the responses of the participants. ${ }^{28}$ Evidence abounds in other chronic disease conditions like diabetes especially in Ghana, which found that chronic disease patients make several causal attributions rooted in the supernatural. ${ }^{28}$ These findings underscore the need for a multidisciplinary approach, which involves faith-based practitioners and healthcare professionals, who will work by using their strengths for the benefit of the patients.

In this study, it was also found that participants used three key coping strategies: spirituality/religious coping, social support and seeking diversion. Spirituality plays a significant role in the life of the African and for that matter Ghanaians, ${ }^{29}$ therefore, serves as a major resource for the women in coping with the challenges associated with living with breast cancer. ${ }^{29}{ }^{30}$ This finding is consistent with previous studies, which found deferring responsibility to God and personal faith as important resources for coping with breast cancer. ${ }^{13}{ }^{15}$ Ghanaians have been described to be religious, ${ }^{31}$ and it is possible that their reliance on a supreme being may be helpful for them to accept their illnesses. Thus, their spirituality creates some form of protection from the negative emotional states that have been shown to be associated with breast cancer. ${ }^{19}$ Acceptance of a disease has been reported by other studies among women with different cancer types. ${ }^{18} 19$

We also found that social support from family members and friends served as a key coping resource for women living with breast cancer. Evidence in the psycho-oncology literature revealed that social support plays a pivotal role in the treatment of breast cancer and its aftermath. ${ }^{12} 1315$ Social support from family, friends and significant others have been linked to decreased mental health problems such as depression, anxiety and suicidal behaviours and improved quality of life among women living with breast cancer. ${ }^{32-35}$ This finding underscores the need for improved social networks and support systems for women living with breast cancer to cushion them against the negative consequences of the medical treatment and the numerous challenges associated with living with breast cancer.

Interestingly, we found that participants use music and films to divert attention from the breast cancer. Radios and televisions served as the main sources of these music and films, which help women avoid thinking about their predicaments. The use of this coping strategy may relate to a component of cancer-specific coping strategies called cognitive avoidance, ${ }^{14}$ which has been linked to decreased depression and anxiety but improved quality of life among women living with breast cancer. ${ }^{36}{ }^{37}$ Thus, availability and accessibility of television sets for these women living with breast cancer could serve as avenue to lessen their emotional burdens associated with their illness. However, there is the need for the contents of the television and radio programmes to be monitored by national authorities to streamline the contents to promote their health and well-being. This is particularly important in Ghana as a previous study has shown that the television and radio were the main sources of information for women living with breast cancer. ${ }^{4}$

The findings from this study imply that there is the need for oncology healthcare workers to understand how breast cancer is cognitively and emotionally represented by their clients and factor these perceptions into their health communication and treatment strategies. The use of varied coping strategies suggests that oncology healthcare workers need to provide support and encourage patients to participate in activities geared towards recovery as well as increased social networks. The study is, however, limited to only patients receiving care at the chosen health facility, which may not necessarily represent the views of all women living with breast cancer in Ghana. Despite this shortcoming, the information provided may serve as the basis for future studies, which would examine illness perceptions and their influence on the short-term and long-term health outcomes of women living with breast cancer.

\section{Conclusion}

This study was conducted to explore illness perception and coping among women with breast cancer in Ghana. We found that there was a general lack of factual knowledge about breast cancer, which manifested in participants low knowledge or belief of the causes of breast cancer. We, however, found that the majority of our participants believed that their disease can be completely cured, and this belief was rooted in their faith in God and on the medical treatments, which suggests the importance of incorporating some positive religious activities into the overall treatment regimen of the women living with breast cancer. Participants relied predominantly on religious faith and spirituality as key coping strategies in addition to social support from family and friends. Maladaptive coping approaches to living with breast cancer was minimal in our study. However, diversion coping and the use of self-care practices were also reported by the participants. These findings underscore the need for oncology healthcare workers to provide support and encourage patients to participate in activities that are geared towards recovery. Healthcare workers understanding of how breast cancer is cognitively and emotionally represented by patients may influence how they perceive health communication and recommended treatment strategies.

Acknowledgements We are very grateful to the hospital authorities and patients who voluntarily took part in this study.

Contributors NK, KOA and AM-W conceptualised and designed the study. NK conducted all the individuals interviewed. All the authors were involved in the entire data analyses process. NK wrote the draft and KOA and AM-W provided critical feedback and editing to the final version of the manuscript. 
Funding The authors have not declared a specific grant for this research from any funding agency in the public, commercial or not-for-profit sectors.

Competing interests None declared.

Patient consent for publication Not required.

Ethics approval Ethics approvals for this study were obtained from the Scientific and Technical Committee as well as institutional review board of the Korle-Bu Teaching Hospital, Ghana (KBTH-IRB/00035/2016) and from the Humanities and Social Sciences Ethical Committee of the University of KwaZulu-Natal, Durban, South Africa (HSS/1428/016D).

Provenance and peer review Not commissioned; externally peer reviewed.

Data availability statement Data are available upon reasonable request. Due to the nature of the data (audio recordings and transcripts), we are not able to share the raw data. We are able to share upon request the deidentified transcripts to researchers for the purposes of further analysis and comparison or research translation.

Open access This is an open access article distributed in accordance with the Creative Commons Attribution Non Commercial (CC BY-NC 4.0) license, which permits others to distribute, remix, adapt, build upon this work non-commercially, and license their derivative works on different terms, provided the original work is properly cited, appropriate credit is given, any changes made indicated, and the use is non-commercial. See: http://creativecommons.org/licenses/by-nc/4.0/.

ORCID iD

Nuworza Kugbey http://orcid.org/0000-0002-0413-0350

\section{REFERENCES}

1 Aziato L, Clegg-Lamptey JNA. Breast cancer diagnosis and factors influencing treatment decisions in Ghana. Health Care Women Int 2015;36:543-57.

2 Kagee A, Roomaney R, Knoll N. Psychosocial predictors of distress and depression among South African breast cancer patients. Psychooncology 2018;27:908-14.

3 Almutairi KM, Mansour EA, Vinluan JM. A cross-sectional assessment of quality of life of breast cancer patients in Saudi Arabia. Public Health 2016;136:117-25.

4 Kugbey N, Meyer-Weitz A, Oppong Asante K. Access to health information, health literacy and health-related quality of life among women living with breast cancer: depression and anxiety as mediators. Patient Educ Couns 2019;102:1357-63.

5 Kugbey N, Oppong Asante K, Meyer-Weitz A. Doctor-patient relationship mediates the effects of shared decision making on health-related quality of life among women living with breast cancer. S Afr J Psychol 2018:0081246318801159.

6 Kaptein AA, Schoones JW, Fischer MJ, et al. Illness perceptions in women with breast cancer-a systematic literature review. Curr Breast Cancer Rep 2015;7:117-26.

7 Shay LA, Lafata JE. Where is the evidence? A systematic review of shared decision making and patient outcomes. Med Decis Making 2015;35:114-31.

8 Fanakidou I, Zyga S, Alikari V, et al. Mental health, loneliness, and illness perception outcomes in quality of life among young breast cancer patients after mastectomy: the role of breast reconstruction. Qual Life Res 2018;27:539-43.

9 Hopman P, Rijken M. Illness perceptions of cancer patients: relationships with illness characteristics and coping. Psychooncology 2015;24:11-18

10 Tang L, Fritzsche K, Leonhart R, et al. Emotional distress and dysfunctional illness perception are associated with low mental and physical quality of life in Chinese breast cancer patients. Health Qual Life Outcomes 2017;15:231.

11 Kahissay MH, Fenta TG, Boon H. Beliefs and perception of ill-health causation: a socio-cultural qualitative study in rural north-eastern Ethiopia. BMC Public Health 2017:17:124.

12 Anagnostopoulos F, Vaslamatzis G, Markidis M. Coping strategies of women with breast cancer: a comparison of patients with healthy and benign controls. Psychother Psychosom 2004;73:43-52.
13 Hajian S, Mehrabi E, Simbar M, et al. Coping strategies and experiences in women with a primary breast cancer diagnosis. Asian Pac J Cancer Prev 2017;18:215-24.

14 Kugbey N, Meyer-Weitz A, Oppong Asante K. Mental adjustment to cancer and quality of life among women living with breast cancer in Ghana. Int J Psychiatry Med 2019;54:217-30.

15 Mehrabi E, Hajian S, Simbar M, et al. Coping response following a diagnosis of breast cancer: a systematic review. Electron Physician 2015;7:1575-83.

16 Richardson EM, Schüz N, Sanderson K, et al. Illness representations, coping, and illness outcomes in people with cancer: a systematic review and meta-analysis. Psychooncology 2017;26:724-37.

17 Kvillemo P, Bränström R. Coping with breast cancer: a meta-analysis. PLoS One 2014;9:e112733.

18 Binka C, Nyarko SH, Awusabo-Asare K, et al. "I always tried to forget about the condition and pretend I was healed": coping with cervical cancer in rural Ghana. BMC Palliat Care 2018:17:24

19 Bonsu AB, Aziato L, Clegg-Lamptey JNA. Living with advanced breast cancer among Ghanaian women: emotional and psychosocial experiences. International Journal of Palliative Care 2014;2014:1-9.

20 Alhassan RK, Nketiah-Amponsah E, Spieker N, et al. Assessing the impact of community engagement interventions on health worker motivation and experiences with clients in primary health facilities in Ghana: a randomized cluster trial. PLoS One 2016;11:e0158541.

21 Clegg-Lamptey JNA, Dakubo JCB, Attobra YN. Psychosocial aspects of breast cancer treatment in Accra, Ghana. East Afr Med J 2009;86:348-53.

22 Smith JA, Osborn M. Pain as an assault on the self: an interpretative phenomenological analysis of the psychological impact of chronic benign low back pain. Psychol Health 2007:22:517-34.

23 Storey L. Doing interpretative phenomenological analysis. analysing qualitative data in psychology, 2007: 51-64.

24 Freedman RA, Kouri EM, West DW, et al. Association of breast cancer knowledge with receipt of guideline-recommended breast cancer treatment. J Oncol Pract 2016;12:e613-25.

25 Sivendran S, Jenkins S, Svetec S, et al. Illness understanding of oncology patients in a community-based cancer Institute. $J$ Oncol Pract 2017;13:e800-8.

26 Fischer MJ, Wiesenhaan ME, Does-den Heijer A, et al. From despair to hope: a longitudinal study of illness perceptions and coping in a psycho-educational group intervention for women with breast cancer. Br J Health Psychol 2013;18:526-45.

27 de-Graft Aikins A, Ad-G A. Healer Shopping in Africa: new evidence from rural-urban qualitative study of Ghanaian diabetes experiences. BMJ 2005;331:737.

28 Ad-G A. Exploring biomedical and ethnomedical representations of diabetes in Ghana and the scope for cross-professional collaboration: a social psychological approach to health policy. Social Science Information 2002;41:625-52.

29 Mbiti JS. African religions \& philosophy. Heinemann, 1990.

30 Mbiti JS. Introduction to African religion. Waveland Press, 2015

31 Adu-Gyamfi A. Connecting religion to homeownership: exploring local perspectives in Ghana. Cities 2020;96:102441.

32 Haugland T, Wahl AK, Hofoss D, et al. Association between general self-efficacy, social support, cancer-related stress and physical health-related quality of life: a path model study in patients with neuroendocrine tumors. Health Qual Life Outcomes 2016:14:11

33 Lim J-won, Yi J, Zebrack B. Acculturation, social support, and quality of life for Korean immigrant breast and gynecological cancer survivors. Ethn Health 2008:13:243-60.

34 Matthews EE, Cook PF. Relationships among optimism, well-being, self-transcendence, coping, and social support in women during treatment for breast cancer. Psychooncology 2009;18:716-26.

$35 \mathrm{Ng} \mathrm{CG}$, Mohamed S, See MH, et al. Anxiety, depression, perceived social support and quality of life in Malaysian breast cancer patients: a 1-year prospective study. Health Qual Life Outcomes 2015;13:1-9.

36 Kulpa M, Kosowicz M, Stypuła-Ciuba BJ, et al. Anxiety and depression, cognitive coping strategies, and health locus of control in patients with digestive system cancer. Prz Gastroenterol 2014:9:329-35.

37 Saita E, Acquati C, Kayser K. Coping with early stage breast cancer: examining the influence of personality traits and interpersonal closeness. Front Psychol 2015;6:88. 